\title{
Evaluation of Vascularity and Colour Doppler Blood Flow in Uterine Myometrium after Delivery
}

\author{
Shideh Ariana ${ }^{1}$, Vajiheh Marsoosi ${ }^{2}$, Ashraf Jamal ${ }^{3}$, Mahsa Naemi ${ }^{4}$, Maryam Nurzade $^{5}$, Maryam Maktabi $^{6}$, \\ Somayeh Khanjani ${ }^{7}$, Nasrin Mansouri ${ }^{8}$
}

${ }^{1}$ Department of Obstetrics and Gynaecology, Tehran University of Medical Sciences, Tehran, Iran. ${ }^{2}$ Department of Obstetrics and Gynaecology, School of Medicine, Shariati Hospital, Tehran University of Medical Sciences, Tehran, Iran. 3Department of Obstetrics and Gynaecology, School of Medicine, Shariati Hospital, Tehran University of Medical Sciences, Tehran, Iran. ${ }^{4}$ Department of Obstetrics and Gynaecology, School of Medicine, Shariati Hospital, Tehran University of Medical Sciences, Tehran, Iran. ${ }^{5}$ Department of Obstetrics and Gynaecology, School of Medicine, Shariati Hospital, Tehran University of Medical Sciences, Tehran, Iran. ${ }^{6}$ Department of Obstetrics and Gynaecology, Tehran University of Medical Sciences, Tehran, Iran. ${ }^{7}$ Department of Obstetrics and Gynaecology, Tehran University of Medical Sciences, Tehran, Iran. ${ }^{8}$ Department of Obstetrics and Gynaecology, Tehran University of Medical Sciences, Tehran, Iran.

\section{ABSTRACT}

\section{BACKGROUND}

The physiology of postpartum period is still unknown. The aim of performing this study was evaluation of vascularity and colour Doppler blood flow in uterine myometrium after delivery.

\section{METHODS}

This cross-sectional study was conducted on 153 women undergoing caesarean section or vaginal delivery who were referred to the Shariati Hospital (Tehran-Iran) in 2018. All women underwent a transabdominal ultrasound examination the following day and one week after parturition. Six weeks later, the patients underwent transvaginal ultrasound. Enhanced myometrial vascularity is seen in ultrasound as a tubular echolucent view in the inner, middle, and outer region of the myometrium. Peak Systolic Velocity (PSV), Resistance Index (RI), and Pulsatility Index (PI) were calculated for hypervascular myometrial regions by Doppler. Endometrial thickness was measured, and the uterus was checked for presence or absence of pregnancy residue.

\section{RESULTS}

Mean age of participations was $30.43 \pm 5.63$ years. Nearly $80 \%$ of them had no history of abortion and delivery type in 110 (71\%) was caesarean. In 105 (67.7\%) cases, placental location was anterior. Uterine vascularity one day, one week and six weeks after delivery was significantly higher in women with placenta remnants $(p<0.05)$. Means value for RI one and six weeks after delivery in women with posterior placenta location was significantly higher than other groups $(p<0.05)$

\section{CONCLUSIONS}

Our findings showed that placental remnants and endometrial thickness one day after delivery were in relation with uterine vascularity one day, one week and six weeks after delivery. In the present study, women with posterior placental location had higher resistance index than other groups.

\section{KEY WORDS}

Vascularity, Doppler, Uterine Myometrium
Corresponding Author:

Shideh Ariana,

Tehran University of Medical Sciences,

Tehran, Iran.

E-mail: shideh.ryn23@yahoo.com

DOI: $10.14260 /$ jemds/2019/773

Financial or Other Competing Interests: None.

How to Cite This Article:

Ariana S, Marsoosi V, Jamal A, et al. Evaluation of vascularity and colour doppler blood flow in uterine myometrium after delivery. J. Evolution Med. Dent. Sci. 2019;8(48):3579-3582, DOI:
Submission 05-10-2019,

Peer Review 14-11-2019,

Acceptance 20-11-2019,

Published 02-12-2019. 


\section{BACKGROUND}

The uterus weight during postpartum period is about one $\mathrm{Kg}$ which is affected by a physiological involution and change to condition of before of pregnancy.(1) The physiology of postpartum period is still unknown. Some of studies focus explain the changes in the size, shape, position, and the tissue of the uterus. The most of studies showed period of normal involution of 6 weeks after normal or pathological delivery in different parities.(2) The process of uterine involution is one of the main functions in the postpartum period that affected in pathological status including uterine infection and haemorrhage.(1) A few studies determine Doppler evaluations of uterine arteries during the normal involution period and it is very limit.(3,4) The vascular changes of continues in the myometrium for long during have been showed in gestational trophoblastic disease. (5) Doppler ultrasound has been applied to measure flow resistance indices of the uterine arteries during normal and pathological pregnancies and during labour.(6)

Patterns of abnormal uterine vascular in colour Doppler examination without evidence of placenta remains have been reported after women pregnancy.(7) Bosch et al. in 2002 reported that the uterine ultrasound and colour Doppler features after pregnancy can be valuable for the management of abnormal haemorrhage in the postpartum period.(8) Some studies showed that pulsatility indices (PI) decreased in the second trimester and remained low until the fourth week after delivery.(9) Also, resistance index (RI) of the uterine arteries from the first day postpartum continually increased, and in 4-6 weeks after delivery reached to non-pregnant values. $(10)$

Due to limited study in this field, the aim of performing of the current study was evaluation of vascularity and colour Doppler blood flow in uterine myometrium after delivery in Tehran, Iran.

\section{METHODS}

\section{Study Design}

This cross-sectional study was conducted on 153 women undergoing caesarean section or vaginal delivery who were referred to the Shariati hospital (Tehran-Iran) between Aprils to July 2018.

\section{Eligibility Criteria}

Diabetes or hypertensive patients or women with multiple pregnancy or cardiovascular complications or renal failure and mothers with IUGR born child were excluded from study. Pregnant women had given birth at between the $37^{\text {th }}$ and $42^{\text {th }}$ gestational week who were willing to participate to the study were considered as inclusion criteria. All included patients gave written consent and accepted to participate in study.

\section{Procedure}

All women underwent a transabdominal ultrasound examination the following day and one week after parturition using a Philips affinity 70 ultrasound device with convex c5-1 MHz probe, including colour Doppler imaging. Six weeks later, the patients underwent transvaginal ultrasound with the C9-4 MH probe. Enhanced myometrial vascularity is seen in ultrasound as a tubular echolucent view in the inner, middle, and outer region of the myometrium. Peak systolic velocity (PSV), Resistance index (RI), and Pulsatility index (PI) were calculated for hypervascular myometrial regions by Doppler. Endometrial thickness was measured, and the uterus was checked for presence or absence of pregnancy residue. Demographic and medical history of patients including age, gravidity, parity, gestational age, fetal weight, placental location, status of use of uterotonic drugs, lactation, hemoglobin level, and pre- and postpartum bleeding were compared.

\section{Data Analysis}

Qualitative data were presented with frequency and percentage and quantitative variables were presented with mean \pm SD. Categorical variables were compared using chisquare test and continuous variables were compared using student t. test and one-way ANOVA. All the analyses were done using SPSS (Version 23) (SPSS Inc., Illinois, USA). P value less than 0.05 was considered as significant.

\section{Ethical Considerations}

Ethical approval for the study was obtained from the institutional review board of Tehran University of Medical Sciences according to Helsinki declaration. (Ethic code: IR.TUMS.MEDICINE.REC.1397.816).

\section{RESULTS}

A total of 153 women entered the study. The patients' characteristics are summarized in table 1 for continues and in table 2 for categorical variables. Mean age was $30.43 \pm 5.63$ year and $60 \%$ of them were in $25-35$ years age group. $38.7 \%$ were overweight and mean BMI was $28.31 \pm 4.62 \mathrm{Kg} / \mathrm{m}^{2}$. PSV was decreasing $(34.06 \pm 14.04$ in one day after delivery to $15.53 \pm 5.66$ for 6 weeks after delivery. In return PI and RI were increasing. $78.8 \%$ had no history of abortion and delivery type in $110(71 \%)$ was caesarean. The proportion of bleeding during 24 hours after delivery and bleeding after 24 hours of delivery was $11.6 \%$ and $2.6 \%$, respectively. In 105 (67.7\%) placental location was anterior.

\begin{tabular}{|c|c|c|}
\hline Variable & Mean & Std. Deviation \\
\hline Age (Year) & 30.43 & 5.63 \\
\hline Weight (Kg) & 74.33 & 13.05 \\
\hline Height (cm) & 162.00 & 5.51 \\
\hline BMI & 28.31 & 4.62 \\
\hline Birth weight (gr) & 3197.92 & 400.50 \\
\hline Hb level one day before delivery & 12.68 & 1.04 \\
\hline Hb level one day after delivery & 11.48 & 1.22 \\
\hline Hb level 6 week after delivery & 11.70 & 3.04 \\
\hline PSV one day after delivery & 34.06 & 14.04 \\
\hline PSV one week after delivery & 24.80 & 10.15 \\
\hline PSV 6 week after delivery & 15.53 & 5.66 \\
\hline PI one day after delivery & 0.74 & 0.45 \\
\hline PI one week after delivery & 0.85 & 0.86 \\
\hline PI 6 week after delivery & 1.07 & 0.52 \\
\hline RI one day after delivery & 0.47 & 0.16 \\
\hline RI one week after delivery & 0.49 & 0.16 \\
\hline RI 6 week after delivery & 0.57 & 0.20 \\
\hline Days with bleeding & 17.64 & 10.37 \\
\hline Table 1. Women's Characteristics (Mean Values \pm Standard Deviation) \\
\hline PSV: Peak systolic velocity, RI: Resistance index, PI: Pulsatility index \\
\hline \multicolumn{2}{|c|}{} \\
\hline \multicolumn{2}{|c|}{} \\
\hline
\end{tabular}




\begin{tabular}{|c|c|c|c|}
\hline \multicolumn{2}{|c|}{ Variable } & Frequency & Percent \\
\hline \multirow{3}{*}{ Age (Year) } & $<25$ year & 25 & 16.1 \\
\hline & 25-35 year & 93 & 60.0 \\
\hline & $>35$ year & 37 & 23.9 \\
\hline \multirow{3}{*}{ BMI Category } & Normal & 40 & 25.8 \\
\hline & Overweight & 60 & 38.7 \\
\hline & Obese & 53 & 34.2 \\
\hline \multirow{4}{*}{ Gravidity } & 1 & 40 & 25.8 \\
\hline & 2 & 54 & 34.8 \\
\hline & 3 & 28 & 18.1 \\
\hline & $\geq 4$ & 33 & 21.2 \\
\hline \multirow{4}{*}{ Abortion } & 0 & 116 & 74.8 \\
\hline & 1 & 26 & 16.8 \\
\hline & 2 & 11 & 7.1 \\
\hline & 3 & 2 & 1.3 \\
\hline \multirow{2}{*}{ Delivery type } & NVD & 45 & 29.0 \\
\hline & Caesarean & 110 & 71.0 \\
\hline \multirow{2}{*}{$\begin{array}{l}\text { Bleeding during } 24 \\
\text { hours after delivery }\end{array}$} & Yes & 18 & 11.6 \\
\hline & No & 137 & 88.4 \\
\hline \multirow{2}{*}{\begin{tabular}{|c|}
$\begin{array}{c}\text { Bleeding after } 24 \text { hours } \\
\text { of delivery }\end{array}$ \\
\end{tabular}} & Yes & 4 & 2.6 \\
\hline & No & 151 & 97.4 \\
\hline \multirow{3}{*}{ Placental location } & Anterior & 76 & 49.0 \\
\hline & Posterior & 68 & 43.9 \\
\hline & Fundal & 11 & 7.1 \\
\hline \multirow{3}{*}{ Vascularity location } & Anterior & 105 & 67.7 \\
\hline & Posterior & 40 & 25.8 \\
\hline & Fundal & 10 & 6.5 \\
\hline \multirow{2}{*}{$\begin{array}{l}\text { Vascularity one day } \\
\text { after delivery }\end{array}$} & Yes & 80 & 51.6 \\
\hline & No & 75 & 48.4 \\
\hline \multirow{2}{*}{$\begin{array}{c}\text { Vascularity one week } \\
\text { after delivery }\end{array}$} & Yes & 68 & 43.9 \\
\hline & No & 19 & 12.3 \\
\hline \multirow{2}{*}{$\begin{array}{c}\text { Vascularity } 6 \text { week after } \\
\text { delivery }\end{array}$} & Yes & 4 & 2.6 \\
\hline & No & 41 & 26.5 \\
\hline \multicolumn{4}{|c|}{ Table 2. Women's Characteristics (Frequency (\%) } \\
\hline
\end{tabular}

\begin{tabular}{|c|c|c|c|c|}
\hline \multirow{2}{*}{\multicolumn{2}{|c|}{ Variable }} & \multicolumn{2}{|c|}{$\begin{array}{l}\text { Placental } \\
\text { Remnants }\end{array}$} & \multirow[t]{2}{*}{ p } \\
\hline & & Yes & No & \\
\hline \multirow{2}{*}{$\begin{array}{l}\text { Uterine vascularity one day } \\
\text { after delivery }\end{array}$} & Yes & 15(78.9) & $4(21.1)$ & \multirow{2}{*}{0.01} \\
\hline & No & $65(47.8)$ & $71(52.2)$ & \\
\hline \multirow{2}{*}{$\begin{array}{l}\text { Uterine vascularity one week after } \\
\text { delivery }\end{array}$} & Yes & $6(54.55)$ & $5(45.45)$ & \multirow{2}{*}{0.005} \\
\hline & No & $13(17.11)$ & $63(82.89)$ & \\
\hline \multirow{2}{*}{$\begin{array}{c}\text { Uterine vascularity six week after } \\
\text { delivery }\end{array}$} & Yes & $2(25)$ & $6(75)$ & \multirow{2}{*}{0.077} \\
\hline & No & $2(5.41)$ & 35 (94.59) & \\
\hline \multirow{2}{*}{ Delivery type } & NVD & $13(28.9)$ & $32(71.1)$ & \multirow{2}{*}{$<0.001$} \\
\hline & Caesarean & $6(5.5)$ & $104(94.5)$ & \\
\hline \multirow{5}{*}{ Induction } & No & 11(10.19) & 97(89.81) & \multirow{5}{*}{0.28} \\
\hline & EASI oneway & 0 & $1(100)$ & \\
\hline & One-way misoprostol & $2(33.33)$ & $4(66.67)$ & \\
\hline & One-way oxytocin & $5(19.23)$ & $21(80.77)$ & \\
\hline & More than one way & $1(7.69)$ & $12(92.31)$ & \\
\hline \multicolumn{5}{|c|}{$\begin{array}{l}\text { Table 3. Relation between Placental Remnants with Uterine } \\
\text { Vascularity Status, Delivery Type and Induction Type }\end{array}$} \\
\hline NVD: Natural vaginal deliver & ASI: extra amnic & aline $\mathrm{i}$ & & \\
\hline
\end{tabular}

\begin{tabular}{|c|c|c|c|c|}
\hline \multirow{2}{*}{\multicolumn{2}{|c|}{ Variable }} & \multicolumn{2}{|c|}{$\begin{array}{c}\text { Endometrial } \\
\text { Thickness One Day } \\
\text { after Delivery }\end{array}$} & \multirow[t]{2}{*}{$\mathbf{p}$} \\
\hline & & $<8 \mathrm{~mm}$ & $>8 \mathrm{~mm}$ & \\
\hline \multirow{2}{*}{ Uterine vascularity one day after delivery* } & Yes & $45(45.92)$ & $35(62.5)$ & \multirow{2}{*}{0.048} \\
\hline & No & $53(54.08)$ & $21(37.5)$ & \\
\hline \multirow{2}{*}{ Bleeding during 24 hours after delivery } & Yes & $10(55.56)$ & $8(44.44)$ & \multirow{2}{*}{0.41} \\
\hline & No & $89(65.44)$ & $47(34.56)$ & \\
\hline \multirow{2}{*}{ Bleeding after 24 hours of delivery } & Yes & $3(75)$ & $1(25)$ & \multirow{2}{*}{0.89} \\
\hline & No & $96(64)$ & $54(36)$ & \\
\hline \multicolumn{5}{|c|}{$\begin{array}{l}\text { Table 4. Relation between Endometrial Thickness with Uterine } \\
\text { Vascularity Status and Bleeding after Delivery }\end{array}$} \\
\hline
\end{tabular}

\begin{tabular}{|c|c|c|c|c|c|c|}
\hline \multirow[t]{2}{*}{ Variable } & \multicolumn{2}{|c|}{ Delivery type } & \multirow{2}{*}{$\mathbf{p}$} & \multicolumn{2}{|c|}{$\begin{array}{l}\text { Placental } \\
\text { remnants }\end{array}$} & \multirow[t]{2}{*}{$\mathbf{p}$} \\
\hline & NVD & Caesarean & & Yes & No & \\
\hline PSV one day after delivery & $39.4 \pm 14.18$ & $31.87 \pm 13.45$ & 0.23 & $39.67 \pm 14.24$ & $33.27 \pm 13.89$ & 0.87 \\
\hline \begin{tabular}{|l|} 
PSV one week after delivery \\
\end{tabular} & $27.45 \pm 8.27$ & $23.95 \pm 10.59$ & 0.42 & $30.77 \pm 13.4$ & $23.93 \pm 9.39$ & 0.04 \\
\hline \begin{tabular}{|l|} 
PSV 6 week after delivery \\
\end{tabular} & $16.31 \pm 6.6$ & $15.22 \pm 5.32$ & 0.57 & $15.9 \pm 5.97$ & $15.45 \pm 5.67$ & 0.91 \\
\hline PI one day after delivery & $0.75 \pm 0.38$ & $0.74 \pm 0.48$ & 0.23 & $0.85 \pm 0.53$ & $0.73 \pm 0.44$ & 0.45 \\
\hline PI one week after delivery & $0.79 \pm 0.43$ & $0.87 \pm 0.96$ & 0.55 & $0.82 \pm 0.46$ & $0.86 \pm 0.91$ & 0.78 \\
\hline PI 6week after delivery & $1.05 \pm 0.39$ & $1.08 \pm 0.57$ & 0.03 & $0.96 \pm 0.52$ & $1.09 \pm 0.53$ & 0.59 \\
\hline RI one day after delivery & $0.48 \pm 0.15$ & $0.47 \pm 0.17$ & 0.26 & $0.5 \pm 0.17$ & $0.47 \pm 0.16$ & 0.8 \\
\hline \begin{tabular}{|l|} 
RI one week after delivery \\
\end{tabular} & $0.5 \pm 0.15$ & $0.48 \pm 0.16$ & 0.68 & $0.47 \pm 011$ & $0.49 \pm 0.16$ & 0.4 \\
\hline RI 6week after delivery & $0.59 \pm 0.13$ & $0.57 \pm 0.22$ & 0.012 & $0.54 \pm 0.19$ & $0.58 \pm 0.2$ & 0.64 \\
\hline \multicolumn{7}{|c|}{$\begin{array}{c}\text { Table 5. PSV, PI and RI Mean Values in 1, } 7 \text { and } 42 \text { Days after } \\
\text { Delivery by Delivery Type and Placental Remnants }\end{array}$} \\
\hline
\end{tabular}

\begin{tabular}{|c|c|c|c|c|}
\hline \multirow{2}{*}{ Variable } & \multicolumn{3}{|c|}{ Placental Location } & \multirow{2}{*}{$p$} \\
\cline { 2 - 4 } & Anterior & Posterior & Fundal & \\
\hline PSV one day after delivery & $32.83 \pm 14.45$ & $34.93 \pm 14.04$ & $37.2 \pm 11.1$ & 0.5 \\
\hline PSV one week after delivery & $24.64 \pm 11.08$ & $24.94 \pm 9.05$ & $25.42 \pm 8.7$ & 0.98 \\
\hline PSV 6 week after delivery & $14.69 \pm 4.2$ & $16.5 \pm 7.2$ & $17.07 \pm 7.66$ & 0.52 \\
\hline PI one day after delivery & $0.78 \pm 0.45$ & $0.71 \pm 0.47$ & $0.74 \pm 0.34$ & 0.68 \\
\hline PI one week after delivery & $0.75 \pm 0.44$ & $1.07 \pm 1.32$ & $0.57 \pm 0.15$ & 0.19 \\
\hline PI 6 week after delivery & $0.96 \pm 0.55$ & $1.27 \pm 0.45$ & $0.96 \pm 0.44$ & 0.16 \\
\hline RI one day after delivery & $0.48 \pm 0.17$ & $0.45 \pm 0.16$ & $0.48 \pm 0.14$ & 0.5 \\
\hline RI one week after delivery & $0.46 \pm 0.12$ & $0.55 \pm 0.20$ & $0.42 \pm 0.08$ & 0.023 \\
\hline RI 6 week after delivery & $0.55 \pm 0.2$ & $0.66 \pm 0.15$ & $0.4 \pm 0.22$ & 0.034 \\
\hline \multicolumn{5}{|c|}{ Table 6. PSV, PI and RI Mean Values in 1, 7 and 42 Days after } \\
Delivery by Placental Location \\
\hline
\end{tabular}

In table 3 Relation between Placental remnants with uterine vascularity status, delivery type and induction type is presented. Uterine vascularity one day, one week and six weeks after delivery was significantly higher in women with placental remnants $(\mathrm{p}<0.05)$. Women with NVD delivery had significantly higher rate of Placental remnants $(25 \%$ vs. $5.41 \%, \mathrm{p}<0.001$ ).

Table 4 shows that there is a significant relation between endometrial thickness one day after delivery with uterine vascularity, so that in women with endometrial thickness one day after delivery more than $8 \mathrm{~mm}$ the percentage of uterine vascularity were higher $(p=0.048)$, but in these women the rate of bleeding after 24 hour of delivery was not significant $(\mathrm{p}=0.89)$.

PSV, PI and RI mean values in 1, 7 and 42 days after delivery by delivery type and placental remnants are shown in table 5. As shown PSV one week after delivery was significantly higher in patients with placental remnants $(30.77 \pm 13.4$ vs. $23.93 \pm 9.39$, p=0.04). PI 6 week after delivery was significantly higher in patients with caesarean delivery (1.08 \pm 0.57 vs. $1.05 \pm 0.39, p=0.03$ ), while RI 6 week after delivery was significantly higher in patients with NVD delivery $(0.59 \pm 0.13$ VS. $0.57 \pm 0.22, p=0.012)$. As shown in table 6 means value for RI one and six weeks after delivery in women with posterior placental location was significantly higher than other groups $(\mathrm{p}<0.05)$.

\section{DISCUSSION}

Our findings showed that uterine vascularity one day, one week and six weeks after delivery was significantly higher in women with placental remnants. Also, there is a significant relation between endometrial thickness one day after delivery with uterine vascularity. In present study, the mean of RI one and six weeks after delivery in women with posterior placental location was significantly higher than other groups. Areas of enhanced myometrial vascularity are seen in early postpartum. These areas located at the former placental site and within 6 weeks after delivery, usually are disappear.

Van den Bosch et al. reported that Enhanced myometrial vascularity was associated with retained placental tissue.(8) Therefore, this is in line with our findings. The retained placental tissue was more frequently seen after instrumental removal of the placental, in patients who needed blood transfusion in the early postpartum, and in multigravidas.(8) Other study by Van Schoubroeck in 2003 reported that Areas of enhanced myometrium vascularity were visualized in $50.5 \%$ and $3.9 \%$ of patients on the third day and the sixth week.(11) 
Colour Doppler examination diagnosed areas of enhanced vascularity in $8.3 \%$ of women. The most of patients were focal areas of one or more vessels. Abnormal vascularity extended over a large area of the myometrium and placental remnants were diagnosed in $2.6 \%$ and $6.75 \%$ of patients, respectively. The miscarriage in first or second trimester, instrumental delivery of the placental, presence of placental remnants and a shorter interval between last pregnancy and the examination were significance factors in predicting enhanced vascularity. ${ }^{(8)}$

Our study showed that the mean of RI one and six weeks after delivery in women with posterior placental location was significantly higher than other groups. However, RI in the uterine artery in the normal postpartum can help us to better understand normal physiology, and to better interpret pathophysiology of the postpartum.

Our study had some limitations. (a) The design of this study was cross-sectional; we proposed this study was performed in a design of large cohort for evaluating of longtime complication. (b) Women should have performed uterine perfusion ultrasound at different times in postpartum, this could limit the frequency of patient referrals. Therefore, we decreased this limitation by giving training to patients and free visits for performing of ultrasound.

\section{CONCLUSIONS}

Uterine vascularity one day, one week and six weeks after delivery was significantly higher in women with placental remnants. Also, there is a significant relation between endometrial thickness one day after delivery with uterine vascularity. In the present study, the mean of RI one and six weeks after delivery in women with posterior placental location was significantly higher than in other groups.

\section{ACKNOWLEDGEMENT}

This study was supported by Tehran University of Medical Sciences (TUMS). Authors thank the participants as well as staff of Shariati Hospitals.

\section{REFERENCES}

[1] Kristoschek JH, de Sá RAM, da Silva FC, et al. Ultrasonographic evaluation of uterine involution in the early puerperium. Revista Brasileira de Ginecologia e Obstetrícia 2017;39(04):149-54.
[2] Mulic-Lutvica A, Axelsson 0. Postpartum ultrasound in women with postpartum endometritis, after caesarean section and after manual evacuation of the placenta. Acta Obstetricia et Gynecologica Scandinavica 2007;86(2):210-7.

[3] Fukuda M, Fukuda K, Shimizu T, et al. Ultrasound assessment of lower uterine segment thickness during pregnancy, labour and the postpartum period. Journal of Obstetrics and Gynaecology Canada 2016;38(2):134-40.

[4] Wataganara T, Phithakwatchara N, Komoltri C, et al. Functional three-dimensional sonographic study of the postpartum uterus. The Journal of Maternal Fetal \& Neonatal Medicine 2015;28(18):2221-7.

[5] Alcázar JL. Transvaginal ultrasonography combined with colour velocity imaging and pulsed Doppler to detect residual trophoblastic tissue. Ultrasound in Obstetrics and Gynecology 1998;11(1):54-8.

[6] Harrington K, Cooper D, Lees C, et al. Doppler ultralsound of the uterine arteries: the importance of bilateral notching in the prediction of pre-eclampsia, placental abruption or delivery of a small-for-gestational-age baby. Ultrasound in Obstetrics and Gynecology 1996;7(3):182-8.

[7] Timmerman D, Van den Bosch T, Peeraer K, et al. Vascular malformations in the uterus: ultrasonographic diagnosis and conservative management. European Journal of Obstetrics, Gynecology and Reproductive Biology 2000;92(1):171-8.

[8] Van den Bosch T, Van Schoubroeck D, Lu C, et al. Colour Doppler and gray-scale ultrasound evaluation of the postpartum uterus. Ultrasound in Obstetrics \& Gynecology 2002;20(6):586-91.

[9] Jaffa A, Wolman I, Har-Toov J, et al. Changes in uterine artery resistance to blood flow during puerperium-A longitudinal study. Journal of Maternal Fetal Investigation 1996;6(1):27-30.

[10] Kirkinen P, Dudenhausen J, Baumann H, et al. Postpartum blood flow velocity waveforms of the uterine arteries. The Journal of Reproductive Medicine 1988;33(9):745-8.

[11] Van Schoubroeck D, Van den Bosch T, Scharpe K, et al. Prospective evaluation of blood flow in the myometrium and uterine arteries in the puerperium. Ultrasound in Obstetrics and Gynecology 2004;23(4):378-81. 